\title{
Pilot scheme for the use of low power wind turbines for electricity generation in the Municipality of Las Palmas de Gran Canaria
}

\author{
Ignacio de la Nuez Pestana ${ }^{1}$, Francisco Javier García Latorre ${ }^{1}$ and Alejandro Ramos Martín ${ }^{2}$ \\ ${ }^{1}$ Agencia Local Gestora de la Energía de Las Palmas de Gran Canaria, Edificio Central del Parque Científico-Tecnológico \\ Campus Universitario de Tafira, 35017 Las Palmas de Gran Canaria (Spain) \\ Phone/Fax number:+0034 9284595 85/+0034 9284595 89, e-mail: inuez@algelpgc.es, figarcia@laspalmasgc.es \\ ${ }^{2}$ Escuela de Ingenierías Industriales y Civiles, University of Las Palmas de Gran Canaria, Edificio de Ingenierías, Campus \\ de Tafira, 35017 Las Palmas de Gran Canaria (Spain) \\ Phone/Fax number:+0034 9281933, e-mail: aramos@dip.ulpgc.es
}

\begin{abstract}
An existing renewable energy source within our territory which has not been massively introduced is the low power wind energy. This kind of installations has only been used for electricity generation in off-grid systems. This paper describes a pilot scheme in which five $5 \mathrm{~kW}$ wind turbines will be installed in the Municipality of Las Palmas de Gran Canaria. The first stage has consisted on the determination of the wind potential within the Municipality of Las Palmas de Gran Canaria, which has been determined taking as a reference the data from the study performed by the AEMET (Spanish Meteorological Agency) and the data comprised in the Canary Islands Wind Resource Cartography. Once this has been done, a study of physical variables related to the wind flux over the Canaries has been performed by taking data generated by a computer simulation of weather conditions in the course of a year. After the calculation of the eolic data and after the selection and location of the five turbines has been determined, a description of the turbines to be installed is given along with an overview on the territorial legal framework applicable to this type of installations.
\end{abstract}

\section{Key words}

Renewable energy, Wind resource, Low-power wind turbines.

\section{Introduction}

Wind turbines are devices which convert wind energy into electricity. These installations can fall into different categories depending on, for instance, values such as the power -low power, medium power wind turbines, etc.[1]. A classification attending to the electrical connection would consist on stating the differences between off-grid and grid- connected wind turbines.
With the proposed configuration the generated electricity will be injected into the grid, so that the turbines must generate alternating current at the same frequency and tension as the grid into which the electricity is going to be fed into. Attending to the power of the turbine, there are two big categories:

Medium- and high-power wind turbines: are turbines in a range from 100 kilowatts $(\mathrm{kW})$ to megawatts (MW). The connection of these machines to the grid requires that these installations meet several conditions and standards.

Low-power wind turbines: are turbines which do normally not affect the grid stability and are in a range up to 100 kilowatts (kW). The connection of these devices is carried out in low tension [2], [3].

This paper will focus on grid-connected low power wind turbines. A pilot scheme to install low-power wind turbines will be performed in the Municipality of Las Palmas de Gran Canaria and will involve five 5kW wind turbines aimed at the promotion and building awareness among citizens on this kind of renewable energy source.

\section{Eolic potential}

In this section the origin of the data used for the estimation of the eolic potential is showed as well as the applied mathematical treatment. Finally the resulting information is displayed in a graphic showing the eolic potential in the Municipality of Las Palmas de Gran Canaria [4].

Initially, the origin data has been extracted from the numerical values comprising the Canary Islands Wind Resource Cartography.

This information consists of a description of the main features of the wind resource i.e. wind speed, direction and other parameters, for specific coordinates within the 
Canary Archipelago. These coordinates are integrated in a $100 \mathrm{~m}$ resolution grid.

Moreover, the real data generated by the AEMET for the period 1959 to 2009 has been obtained. The combination of both sources is sufficient to obtain an approximation of the wind potential within the Municipality of Las Palmas de Gran Canaria [5].

The information comprising the Wind Resource Cartography can be applied overall to high- and mediumpower wind turbines, being not the case of low-power wind turbines, whose hub height is normally lower than $40 \mathrm{~m}$. On the other hand, the data from the AEMET consider a hub height of 10 to $60 \mathrm{~m}$. For this reason, wind speed at heights lower than $40 \mathrm{~m}$ must be determined.

This is the methodology that has been used in this study to determine the wind speeds at a height of 30 to $35 \mathrm{~m}$, which are the more common in the case of low-power wind turbines. The expression is:

$$
V=\alpha_{1} \cdot \ln \left(\frac{Z}{40}\right)+V_{40} \quad \text { for } \quad z<40
$$

where the adjustment of the parameter is:

$$
\alpha_{1}=1,0479 \cdot V_{80}+0,6288 \cdot V_{60}-1,7037 \cdot V_{40}
$$

Being $\boldsymbol{V}$ the wind speed at a height $\boldsymbol{z}$, and the parameters $\left(V_{80}, V_{60}, V_{40}\right)$ the speeds obtained from the available information.

To display the information in a simple way, the selected method has been a speed diagram, a color-coded diagram showing the area of the Municipality of Las Palmas de Gran Canaria. Each colored area corresponds to a determined speed. Thus, five different levels of speed have been established in order to simplify the initial determination of the more suitable zones to install a lowpower wind turbine.

A wind speed diagram at a height of $30 \mathrm{~m}$ is showed below:

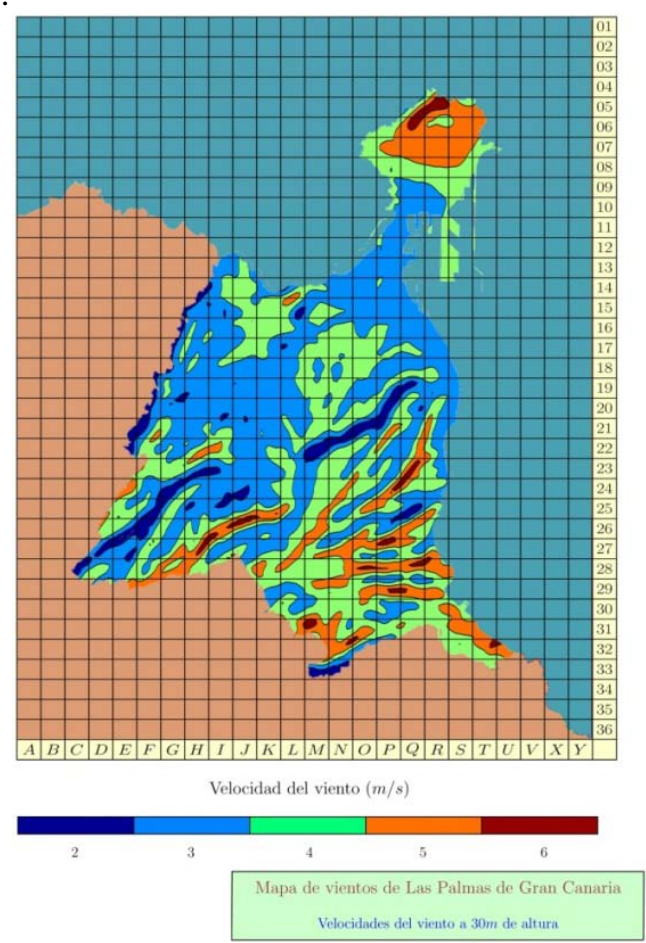

Fig 1. Wind speed map at a height of $30 \mathrm{~m}$.

\section{Low-power wind turbines}

A classification of low-power wind turbines could consist in pointing out the differences attending to the axis of the rotor, being the following the main features.

Horizontal-axis wind turbines are the most common and are normally on top of a tower together with the generator and a multiplication box when necessary. The rotor blades are in the front in order to avoid turbulences. The machine counts with a control device which provides the orientation of the wind turbine. The following are some of the main features:

* Tall towers which allow access to powerful winds.

* Better performance than that of vertical-axis turbines.

* Numerous manufacturers available of this consolidated technology.

On the other hand, vertical-axis wind turbines have the following main features:

* No need for a robust tower.

* Rotor blades are vertical so that there is no need for any wind direction control device, remaining working despite sudden changes in wind direction.

* Can be installed close to the ground, facilitating easy maintenance.

* Can take advantage of ground irregularities favoring wind speed.

* Start working at lower wind speed.

* Are less prone to wind damages under strong wind conditions

* Are easier for birds to avoid.

Taking into consideration all of the above and also that the turbines are to be installed in public transited places, where suitable wind power is available, the more suitable machines are the vertical-axis turbines.

\section{Locations}

The wind turbines site characterization for this pilot scheme is based on several principles such as the intensity of wind speed, the characteristics of the building in which the turbine is to be installed and at last the impact on the environment.

Wind speed at the turbine site must be strong enough in order to make the installation of low power wind turbines available in the market technically viable. This first condition obliges to select the sites within the Municipality with the highest wind power ratios.

Figure 1, obtained from the wind speed map at a height of $30 \mathrm{~m}$, shows the zones with the lowest wind speed intensity, which will be discarded in this study previous to the pilot scheme.

On the contrary, there are two zones within the Municipality which have suitable characteristics 
considering wind speed intensity. The first one is located in the zone of "La Isleta" and the second on the south.

The zone of the "La Isleta" in the north as can be shown is a suitable site, due to the uniformity of wind speed intensity.

The site on the south is idoneous as there the ground elevation provides high wind speed intensity. However, wind speed intensity on this zone is not uniform as in the zone of "La Isleta".

Furthermore the zone of "La Isleta" is directly in the prevailing wind direction and is also one of the most populated areas in the Municipality and thus the most idoneous site for this pilot scheme.

The turbine selection has been based on environmental requirements for these machines as specified below [6]:

- Environmental impact

- Visual impact

- Acoustic impact

All the above requirements must be accompanied by a machine security certificate.

\section{Legal framework}

In this section it is presented a basic compilation of relevant legal documents related to the field of electricity generation using eolic energy. Far from being the complete collection, the following documents are part of the current applicable law.

\subsection{International legislation}

* DiRECTIVE 2001/77/EC OF THE EUROPEAN PARLIAMENT AND OF THE COUNCIL of 27 September 2001 on the promotion of electricity produced from renewable energy sources in the internal electricity market

\subsection{National legislation}

* LAW 54/1197, of November $27^{\text {th }}$, on the Spanish Electricity Sector.

* ROYAL DECREE 661/2007 of 25 May, which regulates the activity of production of electrical energy in special regime.

* ROYAL DECREE LAW 6/2009, of April 30 ${ }^{\text {th }}$, on the adoption of measures for the energy sector and social subsidies.

* ROYAL DECREE 842/2002 of August $2^{\text {nd }}$, by which Low Voltage Electrotechnical Regulations are approved.

* ROYAL DECREE 1955/2000 of December $1^{\text {st }}$, regulating the activities of transport, distribution, commercialization, supply and authorization procedures for electrical power plants.

\subsection{Regional legislation}

The following legislation is applicable to eolic installations in the Canary Islands[7]:
* ORDER of $27^{\text {th }}$ April 2007, for a public call for tenders for the power assignment to new eolic parks connected to the Canarian insular electric grids.

* PECAN (Canary Islands Energy Plan), $29^{\text {th }}$ of March 2007, Parlament of Canary Islands.

* ORDER of $29^{\text {th }}$ of November 2006, which modifies the ORDER of 15th of November 2006 on the regulation of technical and administrative conditions for eolic installations in the Canary Islands.

* ORDER of $15^{\text {th }}$ of November 2006 on the regulation of technical and administrative conditions for eolic installations in the Canary Islands.

* DECREE 32/2006, of $27^{\text {th }}$ of March, on the installation and exploitation of eolic Parks in the Canary Islands.

* DECREE 161/2006, of $8^{\text {th }}$ November, on the authorization, connection and maintenance of electrical installations in the Canary Islands.

In general terms, these compulsory documents try at a regional level to promote, regulate and define the requirements of electricity generating installations using eolic energy in the case of eolic systems with a power higher than $10 \mathrm{~kW}$.

Another aspect to take into consideration in relation to the regional law is that these documents also make mention of eolic installations with investigation and technological development purposes, either connected to the grid or associated to energy storage systems. In those cases, the installations are temporally exempted from the need of obtaining a pre-assignment through a public call for tenders.

\subsection{Local legislation}

The following by-law is applicable in the Municipality of Las Palmas de Gran Canaria:

* Municipal by-law on the environment protection from noise and vibrations.

\section{Localitations definition}

Figure 2 shows the locations selected to install the five low-power wind turbines in within the Municipality.

a) Football Field "Las Coloradas" in the city quarter of "La Isleta".

b) “Plaza de la Música” Square, Av. Príncipe de Asturias, Puerto- Canteras district.

c) Municipal Offices Building at , C/León y Castillo, 270, Ciudad Jardín, distrito Center district.

d) “Fuente Luminosa” Fountain, Av. Alcalde José Ramírez Bethencourt.

e) Zone of "El Rincón”, in the surrounding area of the "Atlante” Monument.

The more suitable areas are those in which wind speed reaches 4 to $6 \mathrm{~m} / \mathrm{s}$. These areas are located in the south of 
the Municipality and in the zone of "La Isleta". From the two, the zone of "La Isleta" is the more idoneous as, there, wind intensity is more uniform.

The impact of the installation over the environment will be low, as low-power wind turbines noise emissions are, according to manufacturers, normally low. The visual impact is also not significant, as these machines are designed to be integrated in urban zones.

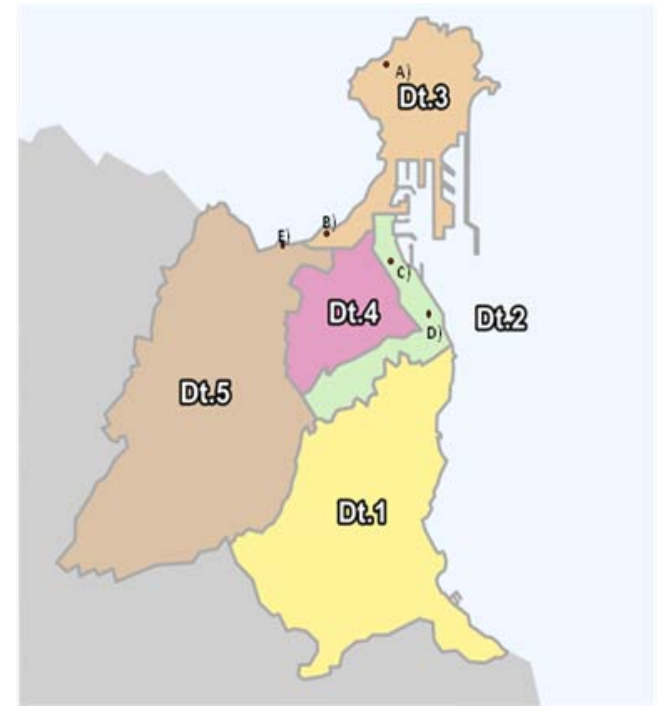

FIG 2. WIND TURBINES LOCATIONS

\subsection{Turbine type}

The wind turbines will be located in urban zones where wind speed intensity is about $5 \mathrm{~m} / \mathrm{s}$, variable and sometimes with turbulences. The fact that turbulences might occur obliges to choose a turbine able to work under the current wind conditions, being in this case necessary to choose the vertical-axis wind turbines over the horizontalaxis turbines. On the other hand, due to the low wind speed intensity it is necessary to choose a turbine with the optimal cut-in speed.

\subsection{Turbine nominal potential}

In order to choose a nominal power, it is important to take into account that the main objective of this study is the performance of a pilot scheme. By this pilot scheme it is expected to obtain the real wind potential within the Municipality of Las Palmas de Gran Canaria. Thus, the foreseen installations must be as simple as possible and meet the minimum specifications required.

All in all the turbines nominal power must not be higher than $10 \mathrm{~kW}$. Otherwise, due to the necessary power assignment process for installations injecting the energy to the grid and the required administrative authorization, the project will be more complex, as can be extracted from the available applicable legislation.

In the case of eolic installations of a power similar or lower than $10 \mathrm{~kW}$ there is no need to apply for the assignment process. The elaboration of a Project is also not required for the definition and the administrative authorization. Only a technical report of the designed is required as established in Annex IV of the DECREE $161 / 2006$, of $8^{\text {th }}$ November, on the authorization, connection and maintenance of electrical installations in the Canary Islands.

\subsection{Additional recommendations}

The information from the eolic potential that has been used is not the more adequate in this experience. For this reason, it will be of interest to install a series of anemometers in several municipal installations in order to obtain real information from wind speed intensity. Having this data, the selection of the turbine would be easier and more precise, as well as the estimation of the energy to be produced. The location of these anemometers should not be limited to those areas with higher wind speed intensity, as there are other zones such as open zones in which there are municipal sport centers, where there is sufficient space for the installation of a turbine.

\section{Conclusion}

In this paper it is exposed a pilot scheme with urban gridconnected low-power wind turbines in the Municipality of Las Palmas de Gran Canaria. The project has as starting point a previous assessment of the wind potential in the Municipality. The legal framework applicable to electricity generation installations using wind power has been considered, highlighting that the current compulsory legislation is applicable to installations with a power higher than $10 \mathrm{~kW}$. Furthermore, a series of relevant parameters have been defined for the turbine selection, for the five systems are to be installed in the urban environment and there are environmental and security requirements for this kind of installations that must be met.

\section{References}

[1] IDAE "PANER Plan Nacional de acción de energías renovables. 2011-2020”.

[2] Pérez-Martínez, M.; Cuesta, M.J.; Cabrera, J.A. "Aerogeneradores de potencia inferior a $100 \mathrm{~kW}$ " CIEMAT. Unidad de Prospectiva y Vigilancia Tecnológica. 2009.

[3] J.L. Rodríguez, J.C. Burgos, S. Amalte "Sistemas Eólicos De Producción de Energía Eléctrica” Editorial Rueda, S.L. ISBN: 84-7207-139-1.

[4] ITC “Cartografía del Recurso Eólico de Canarias” tomos 4, 5, 7 y 8 . www.itccanarias.org/recursoeolico

[5] AEMET "Datos de viento de varias estacones situadas en el término municipal de Las Palmas de Gran Canaria y Aeropuerto de Gran Canaria”, 2009.

[6] IEC "INTERNATIONAL STANDARD IEC 61400-1". 2005-08, Ed. 3.0

[7] Gobierno de Canarias. Consejería de Industria Comercio y Nuevas Tecnologías. "PECAN. Plan Energético de Canarias". 